*Pós-Doutor em Direito (Universidad de Salamanca España). Doutor e Mestre em Direito (UBA/UFPE). Procurador do Estado (PGE/SE - Brasil). Especialista em Docência do Ensino Superior (UCAM/RJ). Graduado em Direito (UCSAL) e Ciências Contábeis (CairuSalvador). Professor do Programa de Pós-Graduação em Direito da Universidade Federal de Sergipe PRODIR. Professor convidado da Escola Judicial do Estado de Sergipe (EJUSE), da Escola Superior de Governo e Administração Pública (ESGAP) e da Fundação de Apoio à Pesquisa e Extensão.

E-mail: pedro.durao@apese.org.br

**Mestranda em Direito pela Universidade Federal de Sergipe - UFS/SE. Pós-graduada em Direito Público pela Pontifícia Universidade Católica de Minas Gerais - PUC/MG. Graduada em Direito pela Universidade Tiradentes. Advogada.

E-mail: julianaaraujopinto@ hotmail.com

\section{Algocracia S/A: O Poder Das Corporações E Seus Algoritmos Nas Sociedades Democráticas}

\author{
Algocracy S/A: The Power Of Corporations And \\ Their Algorithms In Democratic Societies
}

\section{Pedro Durão* Juliana Araujo Pinto**}

Como citar: DURÃO, Pedro; PINTO, Juliana Araujo. Algocracia S/A: OPoder Das Corporações E Seus Algoritmos Nas Sociedades Democráticas. Revista do Direito Público, Londrina, v. 16, n. 3, p. 192-206, dez. 2021. DOI: 10.5433/24157-108104-1.2021v16 n3p.192. ISSN: 1980-511X

Resumo: Com a globalização e o surgimento de novas tecnologias de informação, o fortalecimento do setor empresarial reforçou a inter-relação entre a captura de poder econômico e político das corporações na agenda do século XXI. Logo, o presente artigo propõe verificar os desdobramentos da gestão algorítmica operada pelas corporações e suas implicações no debate público. A metodologia utilizada, de abordagem descritiva, implicou na revisão bibliográfica e documental disponível. Por fim, depreende-se que, no atual paradigma de responsabilidades compartilhadas, garantir a transparência no meio digital, realizar parcerias público-privadas e manter uma dinâmica de diversidade social de mídia no ciberespaço são fundamentais para o funcionamento democrático da sociedade e para a edificação da cidadania empresarial.

Palavras-chave: Algoritmos; Corporações; Democracia; Dados; Tecnologias. Transparência.

\begin{abstract}
With globalization and the emergence of new information technologies, the strengthening of the business sector reinforced the interrelationship between the capture of economic and political power of corporations on the agenda of the 21 st century. Therefore, this article proposes to verify the developments of the algorithmic management operated by the corporations and their implications in the public debate. The methodology used, with a deductive approach, implied the bibliographic and documentary review available. Finally, it appears that, in the current paradigm of shared responsibilities, guaranteeing transparency in the digital environment, making public-private partnerships and dynamics of social media diversity in cyberspace is fundamental for the democratic
\end{abstract}


functioning of society and for the construction of society corporate citizenship.

Keywords: Algorithms. Corporations. Democracy. Data. Technologies. Transparency. 


\section{INTRODUÇÃO}

Historicamente, os atos de trocas e circulações de bens e serviços impulsionaram as relações econômicas, sociais e jurídicas. A própria construção do poder do Estado foi acompanhada pela elevada concentração de capital em todo o globo. Em razão do intenso processo globalizador, do avanço tecnológico e do rompimento de fronteiras comerciais e geográficas, as empresas se tornaram agentes de transformação da sociedade, não só pelo poderio econômico que as detém, como também pela influência que assumem no estímulo à competitividade, na revolução da indústria, na criação de empregos e geração de renda.

Entretanto, através da formação de lobbies, de acordos milionários no Judiciário e do controle do poder midiático, as corporações passaram a exercer influência significativa no processo econômico e político, ditando as regras do jogo democrático de acordo com seus interesses comerciais e com o fluxo de mercado, sob a égide de um novo sistema de governança, denominado de Corporotocracy. Com a expansão dos algoritmos, a Corporocracia deu lugar à Algocracia, ameaçando a sociedade democrática com o poder de filtragem, predileção de hábitos de navegação e cruzamento de informações dos sistemas algoritmos, a serviço das plataformas de tecnologia.

Dessa maneira, o presente trabalho tem como escopo analisar as funções das empresas, principalmente das gigantes de tecnologia na democracia digital, bem como examinar a real relevância dos algoritmos nos processos de tomada de decisão e escolha política, decorrentes da habilidade da gestão algorítmica em organizar, classificar, filtrar e prever comportamentos e ações humanas em sociedade. Ademais, pretende contribuir para com a conscientização da responsabilidade social corporativa e do exercício da função social da empresa.

Para se chegar ao objetivo proposto, optou-se pela metodologia de pesquisa qualitativa e bibliográfica para promover a análise do assunto proposto, lastreada nos ensinamentos do cientista social e especialista em tecnopolítica Sérgio Amadeu da Silveira, bem como a vasta literatura nacional e estrangeira, artigos e revistas digitais, documentos oficiais, notícias e dados quantitativos incorporados à temática em apreço.

Logo, com o fito de problematizar e refletir sobre o papel do setor empresarial e suas novas ferramentas de tecnologia nas sociedades democráticas, o presente trabalho foi divido em três seções. A primeira delas traçará um paralelo entre Corporocracia e Algocracia, destacando o poder de influência política e econômica dos conglomerados empresariais. Em seguida, buscará discorrer acerca do funcionamento do sistema algorítmico e discutir como a filtragem seletiva dos algoritmos implicam nos debates democráticos e na modulação da opinião pública. Ao final, a terceira seção se encarregará de destacar a responsabilidade das plataformas de tecnologia acerca dos conteúdos veiculados no ciberespaço e o papel destas na democracia. 


\section{DA CORPOCRACIA À ALGOCRACIA: O PAPEL DAS GRANDES EMPRESAS NA DEMOCRACIA DIGITAL}

Desde a formação das primeiras civilizações, as relações de poder econômico e poder político sempre estiveram entrelaçadas. Ao longo dos paradigmas de Estado, é possível identificar o jogo dos atores econômicos sobre o processo político, com o intuito de favorecer seus interesses privados. Inserido nesse contexto, a construção do Estado Liberal adveio da luta da burguesia contra o absolutismo e o legado do domínio feudal. Pautado no liberalismo de mercado e da não intervenção estatal, o Estado Liberal eclodiu a conquista por direitos civis e políticos, tais como direito à vida, à propriedade e às liberdades clássicas, dentre estas as de iniciativa e de concorrência.

Como bem pontuado por Soares (2001, p. 269), "o laço que vinculava as funções estatais às leis gerais, protegia o sistema de liberdade codificada do direito privado burguês e a economia de mercado". Segundo o autor, as liberdades e igualdades coadunadas ao Estado eram meramente formais, posto que atendiam apenas aos ensejos da classe burguesa, através do mecanismo do laissez faire, traduzido como um dos principais ideais da economia de mercado, sem que houvesse interferência do governo nas relações privadas.

A crise do Estado Liberal ${ }^{1}$ fez com que o ente estatal marcasse maior presença nas relações individuais em razão do interesse público, criando, assim um novo ciclo, denominado de Estado Social, pelo qual prevalecia a proteção de direitos sociais, econômicos e culturais. Na medida em que se asseguravam prestações positivas de direitos, fundadas na isonomia material, aumentavamse as funções da máquina estatal, ocasionando o seu inchaço.

A política assistencialista e os gastos públicos produzidos por esta, combinados com a crescente expansão da economia capitalista contribuíram para o declínio do Welfare State e o surgimento de novos anseios sociais. Com o avanço da marcha globalizadora e a introdução de novas tecnologias, inaugura-se um novo paradigma, o de Estado Democrático de Direito, apoiado na redefinição dos princípios dos Estado Liberal e Social, no sistema de garantias fundamentais e na participação da sociedade no poder, como característica da democracia (SOARES, 2001, p. $307)$.

Nesse aspecto, o preâmbulo da Constituição Federal de 1988 assevera que os representantes da nação brasileira foram convocados para instituir o Estado Democrático de Direito, sob o qual todo o poder emana do povo ${ }^{2}$, consoante preconiza o art. $1^{\circ}$, parágrafo único da $\mathrm{CF} / 88$. Apesar do ideário de sistema de governo em prol do coletivo e de busca pela concretização do interesse público, a democracia encontra obstáculo na força da economia capitalista contemporânea e de

1 Mário Lúcio Quintão Soares afirma que a classe burguesa acabou por danificar os pilares do Estado Liberal, diante das contradições impostas com o excesso de liberdades e a ausência de proteção a direitos fundamentais básicos. Segundo o professor, a classe burguesa, na busca pelo lucro, "desrespeitou as regras de mercado e eliminou a livre concorrência e a livre iniciativa, concentrando riquezas e acentuando os desníveis sociais (...) surgiram segmentos proletários que, vítimas da miséria e da exclusão social, e gradativamente instruídos por concepções socialistas, adquiriram consciência desta espoliação" (SOARES, 2001, p. 127-128).

2 Aqui compreendido pela ideia de democracia participativa, de legitimação da população não só para garantia de interesses individuais, mas em prol da coletividade, sobretudo quando se trata do ambiente virtual. Nesse diapasão, em discurso proferido no dia 26 de outubro de 1998, Friederich Müller destacou a noção de povo como questão fundamental à democracia, posto que a participação da população nos assuntos de interesse público forma a base jurídica do próprio Estado Democrático de Direito (MÜLLER, 2003, p. 131). 
seus representantes econômicos, que invertem a ordem estatal, priorizando o interesse privado, bem como transferindo o poder das mãos do povo para as mãos do mercado. (BRASIL, 1988).

O poder desproporcional de influência das grandes empresas no sistema político deu origem à Corporocracia ou Corporotocracy, termo utilizado pelos militantes do Movimento Ocupy Wall Street ${ }^{3}$, realizado em 17 de setembro de 2011, na cidade de Manhattan. Manifestações como esta demonstram a crise da representação política e a complexidade da interação entre Estados e corporações, onde o setor empresarial captura a esfera pública e controlam o jogo democrático, através do processo de privatização da democracia, conforme sintetizam Berrón e Gonzáles (2016, n. 8):

É um jogo desigual, que se traduz em: a) crescente privatização da democracia ou seja, um cenário no qual, graças a diversos formas de influência, empresários controlam mecanismos centrais da dinâmica democrática (eleições, trabalho parlamentar, programas, obras, poder judiciário etc.) - que, por sua vez, resulta em b) políticas públicas, leis e acordos internacionais que favorecem os interesses econômicos das grandes corporações transnacionais e redundam em c) maior concentração econômica, que produz d) atores econômicos cada vez mais poderosos em relação às outras esferas da sociedade, cuja existência resulta em e) sociedades mais pobres, tanto em termos econômicos quanto de soberania.

Enquanto que a captura política se dá a partir do influxo desmedido dos atores corporativos em detrimento aos atores sociais nos processos de escolha e tomada de decisão, a captura econômica se realiza através da apropriação de parcela desproporcional das riquezas sociais ou dos bens comuns (BERRÓN E GONZÁLES, 2016, p. 17-19). Em ambos os casos, os mecanismos de captura promovem a supremacia do interesse privado sobre o interesse público e a ampliação dos níveis de desigualdades socioeconômicas, desembocando, ao fim, no enfraquecimento da democracia.

Concomitantemente ao fenômeno da Corporocracia, a nova era democrática, denominada democracia digital enfrenta um novo paradigma: a Algocracia. Nos ensinamentos de Danaher (2016, p. 3), a referida expressão é utilizada com o fito de descrever um sistema de base algorítmica cuja função permite a coleta, a disposição e organização de dados sobre os quais as decisões são tomadas. Para o autor, apesar das qualidades inovadoras dos algoritmos, o uso do sufixo de origem grega cracia confere à Algocracia uma conotação negativa, sobretudo diante da ameaça do referido sistema de governança particular, visto que "os algoritmos estruturam e restringem as maneiras como os humanos dentro desses sistemas interagem uns com os outros, os dados mais relevantes e a comunidade mais ampla afetados por esse sistema" (DANAHER, 2016, p. 3).

Partindo-se da lógica do lucro em redes, isto é, de quanto mais usuários, melhor a performance da empresa, o mercado de dados fatura o equivalente ao Produto Interno Bruto (PBI) de uma série de países, inclusive europeus $(69 . . ., 2018)^{4}$. De acordo com Galindo (2017) o fluxo 3 O protesto pacífico lutava contra as desigualdades e o poder desmedido das grandes corporações sobre o governo norte-americano (KANECK, 2012, p. 8). In: Ocupy Wall Street: A moviment in the making. Disponível em: https:// core.ac.uk/download/pdf/232739499.pdf. Acesso em: 30 jan. 2021.

4 A respeito disso, de acordo com pesquisa realizada pela ONG britânica "Global Justice Now", publicada em 17 
de dados hoje representa um dos principais ativos de gigantes da tecnologia, devido à extensa capacidade de armazenamento de informações e da habilidade dos algoritmos em traçar perfis comportamentais no ciberespaço, tornando-se, inclusive, o petróleo da era digital ${ }^{5}$.

Com a pandemia do novo coronavírus, diversas organizações centralizaram seus dados em grandes corporações a fim de garantir o prosseguimento de suas atividades, a exemplo de universidades públicas e privadas espalhadas pelo país, que em parceria com as empresas de tecnologia, como a Google for Education, concentram dados de alunos, professores e bases de pesquisa para executar tarefas, ministrar aulas e compartilhar materiais, mobilizando, cada vez mais, o mercado da economia informacional. Todavia, tal sistema de dataficação, baseada no behaviorismo e na gestão algorítmica dos dados, pode afetar o debate público e desvirtuar a democracia, como será apresentado a seguir.

\section{UMA ANÁLISE DA CURADORIA ALGORÍTMICA E SEUS EFEITOS NO DISCURSO PÚBLICO NA ERA DIGITAL}

Os algoritmos estão invadindo o cotidiano da sociedade digital, seja nos softwares, seja nas máquinas e robôs, seja no GPS do carro, seja nas redes sociais da Internet. Contudo, inicialmente, é necessário contextualizar a onipresença e a expansão dos algoritmos ou denominados "códigos invisíveis", como bem destaca o especialista em tecnopolítica Sérgio Amadeu da Silveira. Segundo o autor (2019, p. 17) o termo algoritmo tem origem na palavra grega arithmós, que significa número, justificando sua relação com a matemática, e podendo ser conceituado como conjunto de regras encadeadas de forma lógica e inequívoca para solucionar determinado problema, ou simplesmente, uma "sequência de etapas bem definidas para solução abstrata do problema" (SILVEIRA, 2019, p. 18).

Uma das características da curadoria algorítmica é a habilidade no processamento automatizado de dados. Ao armazenar esses dados, a gestão algorítmica molda comportamentos dos usuários em rede, selecionando, filtrando e organizando as informações no ambiente online, a fim de atender as necessidades individuais, através de uma análise preditiva dos interesses dos usuários (STARK et al, p. 10). Entretanto, é nesta personalização de conteúdo em que reside o principal problema, uma vez que as empresas privadas da Internet, impulsionadas pela lógica do lucro em rede anteriormente mencionada, disponibilizam, classificam e veiculam as informações e notícias, com base nas diretrizes econômicas e na popularidade, atendendo aos desejos do mercado

de outubro de 2018, das 100 maiores economias do mundo, 69 são empresas e apenas 31 são países, superando o PIB de diversas nações. Na tabela ora analisada, comparando as cifras econômicas das corporações com a renda orçamentária dos países, a Apple, por exemplo, ocuparia a $29^{a}$ posição, com uma receita de U\$ 229.234.000,00, ao passo que a Suíça seguiria com a $30^{\mathrm{a}}$ posição, com receita de U\$ 223.500.000,00. Disponível em: https://www. globaljustice.org.uk/news/2018/oct/17/69-richest-100-entities-planet-are-corporations-not-governments-figuresshow. Acesso em: 13 abr. 2020.

5 Tradução da expressão the oil of the digital utilizada pela revista americana The Economist para definir o ativo essencial de gigantes da tecnologia, tais como Amazon, Apple, Facebook, Google, Microsft. Disponível em: https:// www.economist.com/leaders/2017/05/06/the-worlds-most-valuable-resource-is-no-longer-oil-but-data. Acesso em: 29 jan. 2021. 
publicitário.

O resultado da atividade algorítmica de filtragem resulta na formação de bolhas de filtro $^{6} \mathrm{e}$ câmaras de $\mathrm{eco}^{7}$, criando aos indivíduos uma imagem distorcida da realidade (SILVEIRA, 2019, p. 78; STARK et al, 2020, p. 15). Em ambas as situações, os usuários, quando expostos apenas a pontos de vistas similares ou notícias personalizadas, afastam-se de discussões relevantes da sociedade. Em um ambiente onde se prioriza número de cliques e conteúdos replicados, o sistema de algoritmos, baseados no comportamento, acabam por empobrecer a diversidade cultural e a pluralidade dos debates e polarizar a sociedade.

No atual cenário de crise sanitária, a rápida propagação de fake news e circulação de mensagens imprecisas pelas redes e plataformas sociais contribuíram para com o negacionismo da doença e a descredibilidade da ciência, mesmo diante de um momento histórico na revolução do conhecimento científico, com a descoberta de vacinas em menos de um ano de pandemia. Assim, resta demonstrado como a disseminação do vírus da desinformação e a atuação dos algoritmos impactam o processo de formação de opinião, ocasionando a fragmentação do discurso público.

Nesse sentido, o professor Sérgio Amadeu da Silveira vem desenvolvendo uma série de estudos voltados aos impactos da curadoria algorítmica na participação política e nos rumos da democracia na era digital, que culminaram na publicação do e-book Democracia e os códigos invisíveis: como os algoritmos estão modulando comportamentos e escolhas políticas. Na obra, Silveira (2019, p. 51) aponta três hipóteses sobre como a tecnologia de algoritmos pode afetar a sociedade democrática. A primeira delas decorre da análise preditiva e da filtragem seletiva do sistema algorítmico, visto que a customização de conteúdos pode restringir discursos em redes, limitados às bolhas de filtro e câmaras de eco, alterando até mesmo as circunstâncias de disputas numa democracia, a qual carece de condições mínimas de equidade para garantir o equilíbrio das forças políticas e a pluralidade dos debates.

A segunda diz respeito à modulação algorítmica do processo de formação da opinião pública e de escolhas. Contudo, faz-se mister salientar que, diferentemente da noção clássica de manipulação, baseada no controle das sociedades de massa, o conceito de modulação aqui proposto pelo cientista político para compreender a atividade algorítmica está intrinsicamente relacionada à concentração ou dispersão de conteúdos em rede para captar a atenção, bem como o modo pelo qual as grandes plataformas operadas por algoritmos selecionam o que pode ser visualizado e o que há de relevante de acordo com as preferências de cada usuário (SILVEIRA, 2019, p. 56-57).

A terceira hipótese suscitada pelo professor $(2019$, p. 60) versa sobre a vigilância pervasiva de consumidores e cidadãos. Além dos governos, as corporações e plataformas de tecnologia detêm nas suas bases algorítmicas mecanismos de decodificação que visam aprender os comportamentos dos consumidores, oferecer produtos e serviços que melhor lhe convêm e até antever gostos e preferências. Ocorre que, a dependência do ser humano à máquina e o controle pervasivo dessas empresas sobre a população pode afetar a democracia, na medida em que o setor empresarial 6 O referido termo foi utilizado pela primeira vez pela ativista da Internet Eli Parisier, na obra The Filter Buble: What the Internet is Hiding from You (STARK et al, 2020, p. 14).

7 Ao contrário das bolhas de filtro, nas câmaras de eco os indivíduos não estão sozinhos, mas expostos em grupo de opiniões semelhantes (STARK et al, 2020, p. 14). 
captura o poder por intermédio do controle organizado de informações, moldando as afetividades, atitudes e visões políticas (DOWBOR, 2016, p. 28).

Apesar da expansão dos algoritmos em diversos segmentos do cotidiano, tais como na produção jornalística, nos setores de logística e na gestão de plataformas online de sites de relacionamento, a sociedade se tornou refém da ofuscação algorítmica operada por empresas, através de um mecanismo invisível e teoricamente neutro. É nesse contexto de formação de nova ordem econômica que surge o capitalismo de vigilância como, fenômeno de "monitoramento automatizado das experiências privadas, realizados por algoritmos inteligentes com a intenção de induzir consumos e comportamentos" (VELOSO, 2020, p. 7).

O capitalismo de vigilância traz complexas questões sociais acerca de valores democráticos. De um lado, encontra-se a liberdade de acesso ilimitada a dados da população, do outro, a falta de privacidade dos consumidores (SILVEIRA, 2019, p. 78; ZUBOFF, 2019, p. 354). Diante desse campo de batalha, qual limite entre o público e o privado na democracia digital? Como proteger os dados pessoais de usuários interconectados pela vigilância oculta de gigantes da tecnologia?

\section{A RESPONSABILIDADE DO SISTEMA CORPORATIVO E OS VALORES DEMOCRÁTICOS NA SOCIEDADE DE INFORMAÇÃO}

Como proposto na seção anterior, a gestão algorítmica das plataformas digitais pode interferir na formação da opinião pública e colocar em risco a democracia, devido a filtragem e análise de predileção do sistema, que acaba isolando grupos e excluindo participantes do debate democrático. O maior perigo desse modelo é que, amparado na ideia de neutralidade e imparcialidade algorítmica, cidadãos desinformados são persuadidos e o nível de privacidade é colocado em cheque, em razão do elevado poder de conhecimento e acesso de dados de gigantes da tecnologia como Google, Facebook, Amazon, abalando a teoria democrática.

No tocante ao estremecimento das bases democráticas, aduz Silveira:

A teoria democrática nunca considerou recomendável a opacidade e a invisibilidade para governos e estruturas de grande poder, principalmente as privadas, que submetem o interesse público à finalidade lucrativa. É impossível considerar democrática a operação oculta dos algoritmos na distribuição de conteúdos nas redes sociais online. Ao contrário, a modulação algorítmica da opinião pública é um grande perigo para a democracia." (SILVEIRA, 2019, p. 78).

Por vezes, a atuação desses conglomerados empresariais, extraindo dados, monitorando o acesso às redes, modulando preferências, gostos e discursos, sem explicar, ao certo, a real intenção de toda essa política de invasão à privacidade atingem uma sério de direitos e garantias fundamentais. Sem contar os efeitos da polarização e da fragmentação de debate político ocasionadas pela curadoria algorítmica, que personalizam as informações e inibem a formação de opinião de 
usuário em rede, dentro de bolhas de filtro ou de grupos específicos (STARK et al, 2020, p. 15-16).

Somado a isso, os conflitos gerados pela vasta desinformação e pela hibridização de conteúdos distorcem a realidade dos fatos e contribuem para o crescente do índice de casos de incivilidade nas redes e para disseminação de discursos de ódio, que atropelam as normas de comunicação saudável, alimentando as ofensas no ciberespaço e violando direitos fundamentais dos indivíduos. Corroborando tal argumento, é possível identificar no mercado algoritmos racistas ${ }^{8}$ que fomentam práticas discriminatórias nas redes sociais.

$\mathrm{Na}$ contramão das campanhas de ódio orquestradas na Internet, a Alemanha adotou uma política regulatória para conter a alastramento de conteúdos ofensivos nas redes, por intermédio da aprovação da German Network Enforcement Act - GNEA, lei alemã de combate a discursos de ódio e incitação da violência, que através de parcerias com Youtube, Facebook, Twitter bloqueiam ou removem conteúdos ilegais. Nessa linha, de acordo com os dados obtidos pela AlgorithWatch em Berlim, cerca de 700.000 mil postagens foram retiradas do ar pelas empresas parceiras da GNEA (STARK et al, 2020, p. 7).

A preocupação central reside no embate da censura injustificada com as restrições à liberdade de expressão no espaço virtual, especialmente porque a tarefa de aplicar leis de contenção e repressão de discursos de ódio e discriminatório está sendo transferida para grandes empresas, operadoras das plataformas digitais. Para Sarlet (2018) a criação de um mecanismo de controle preventivo e não sancionatório que não implique em censura privada injustificada nem silenciamento da liberdade de expressão nas redes sociais é essencial para o equilíbrio de valores fundamentais.

A regulação de dados e conteúdos entre o poder público e o privado também repercute a respeito dos limites do poder corporativo em excluir determinado conteúdo e/ou usuário. $\mathrm{Na}$ expectativa de "fazer valer a lei e a Constituição", as plataformas de tecnologia saíram bloqueando discursos de diferentes ideologias, censurando de forma injustificada movimentos sociais e removendo usuários sem explicação plausível. No tocante a temática, Silveira enfatiza que não se deve comemorar essa troca de papéis, visto que "as sociedades democráticas precisam supervisionar as plataformas, em vez de ser controladas por elas (...) não podem estar acima da Constituição, não podem praticar o despotismo digital" (SILVEIRA, 2021).

Sob essa perspectiva, o direito à liberdade de expressão, à intimidade e privacidade, à segurança e à diversidade social de mídias recobrem, ainda que de forma implícita, o texto constitucional brasileiro, exercendo influência direta nas relações privadas, e consequentemente, nas relações empresariais, que passaram a ser interpretadas sob a ótica da Constituição, dotada de força normativa, resultado do fenômeno da Constitucionalização do Direito.

Diante deste novo paradigma, os demais ramos do devem ser compreendidos e interpretados sob as lentes da Carta Magna, de modo a realizar os valores nela consagrados, conforme assevera Barroso (2005, p. 16). De acordo com o autor, diante da irradiação de princípios e valores 8 Segunda o Organização das Nações Unidas (ONU), a inteligência artificial pode agravar práticas discriminatórias através do uso indevido de algoritmos, sobretudo quando são usados como ferramenta de prevenção e vigilância da polícia, reforçando o preconceito. Disponível em: https://oglobo.globo.com/celina/onu-algoritmos-racistasaumentam-discriminacao-racial-por-servicos-de-seguranca-24768880. Acesso em: 30 jan. 2021. 
fundamentais no sistema jurídico contemporâneo, as normas constitucionais repercutem não só entre os poderes Executivo, Legislativo e Judiciário, como também nas relações de direito privado, entre os particulares.

O Direito Empresarial, como ramo autônomo de direito privado também se submete ao filtro das normas constitucionais, em decorrência da força normativa da Constituição e da nova dogmática de interpretação constitucional, frutos do Neoconstitucionalismo. E um dos aspectos abordados pela constitucionalização do direito é a chamada aplicabilidade dos direitos fundamentais nas relações entre particulares, na tentativa de igualar as relações de poder e garantir determinado equilíbrio entre as partes, principalmente nas tratativas comerciais.

Diferentemente da visão clássica do direito empresarial de busca única e exclusiva pelo lucro, a tutela da empresa é hoje analisada sob uma nova perspectiva, diretamente influenciada pela constitucionalização do direito privado. Hodiernamente, a atividade empresarial necessita estar em conformidade com os princípios constitucionais sedimentados explícita ou implicitamente, tanto no campo do interesse privado quanto no campo do interesse coletivo, a fim de estimular o desenvolvimento harmonioso e equilibrado em comunidade.

Desse modo, é possível observar, ao longo do texto constitucional, diversos princípios aplicáveis às relações empresariais, seja pela livre iniciativa e livre concorrência, seja pela função social da empresa, seja pela boa fé nas relações empresariais, seja pela cooperação para com o desenvolvimento humano sustentável no âmbito corporativo. Além disso, o próprio Supremo Tribunal Federal reforça o posicionamento de que o rol de direitos fundamentais ${ }^{9}$ previstos no art. $5^{\circ}$, caput, da $\mathrm{CF} / 88$, também se estende às pessoas jurídicas, incluindo as empresas

Assim como o direito à privacidade, à segurança e à liberdade no ciberespaço estão implicitamente inseridos no rol de garantias fundamentais do art. $5^{\circ}$, da $\mathrm{CF} / 88$ a partir da interpretação da dignidade humana, o exercício da função social da empresa, também deriva da função social da propriedade. Inserida nos artigos $5^{\circ}$, XXIII e 170, III da Constituição Federal de 1988, nasce como forma de subordinar os valores constitucionais e os direitos fundamentais à atividade empreendedora, conforme observa Gladston Mamede:

O princípio da função social da empresa conduz o enfoque da livre iniciativa não por sua expressão egoísta, como trabalho de um ser humano em benefício de suas próprias metas, mas como iniciativa que, não obstante individual, cumpre um papel na sociedade. A iniciativa individual, portanto, deve ser valorizada e protegida por todos os seus Poderes e órgãos, já que funciona a favor da sociedade. Mas, para além do titular da atividade negocial, o princípio também exige a atenção à atividade em si, percebendo-a como unidade de uma estrutura, um sistema no qual todas as atividades se combinam a bem da sociedade (MAMEDE, 2016, p.47).

Dessa maneira, o interesse econômico, e consequentemente, os lucros da empresa, devem

9 De acordo com Flávia Piovesan, a grande inovação do texto constitucional de 1988 foi de incluir no catálogo de direitos fundamentais, além de direitos civis e políticos, direitos sociais, econômicos e culturais, ao mesmo tempo em que estendeu a titularidade de direitos diante do surgimento de novos sujeitos. (PIOVESAN, 2015, p.111). 
ser combinados com a proteção e promoção da coletividade, aqui compreendida através dos consumidores, dos funcionários, do meio ambiente e de todos aqueles que dependem da sociedade empresária para o seu sustento. Logo, a atuação responsável e a proteção de direitos fundamentais no ambiente corporativo contribuem de forma relevante no processo de desenvolvimento econômico, social e ambiental.

Em razão disso, como rota de fuga às pressões sociais no ciberespaço, a responsabilidade social corporativa parte de uma base estratégica da empresa, de comprometimento dos empresários para com o desenvolvimento econômico, social e sustentável (MELO NETO; FRÓES, 1999, p. 38), envolvendo todos os stakeholders ${ }^{10}$ e fomentando, assim, a cidadania, que vai além da extensão das liberdades civis e sociais, como também das liberdades econômicas e de participação.

Nessa toada, a cidadania empresarial vai transformando a empresa em agente econômico e social, contribuindo, em escala global, com investimentos em bem-estar para os seus funcionários, clientes, fornecedores e parceiros, bem como toda a comunidade. Tal postura de empresa cidadã é muito cobrada, tanto pelo Estado quanto pela própria sociedade, através de um mercado de consumo contemporâneo exigente e consciente ${ }^{11}$, partindo da Corporocracia à Cooperocracia.

Cumpre ressaltar que o funcionamento da democracia depende não só das instituições democráticas, como também da participação coletiva de todos os setores da sociedade, sobretudo das empresas. Isso porque uma democracia saudável carece de um ambiente de discussão de questões políticas relevantes, posto que o desenvolvimento das liberdades de informação e de formação de opinião dependem de debates abertos e discussões públicas que possam ajudar as pessoas no processo de escolhas bem fundamentadas e mudar a realidade social onde vivem (SEN, 2000, p. 97).

A própria noção de democracia e de modelo constitucional no ambiente digital precisam ser ressignificados. Ainda que se crie uma declaração universal de direitos ou uma constituição digital, de caráter transnacional, que reforcem as já conquistadas ao longo dos paradigmas de Estado, o grande ensinamento que fica para a sociedade é que da mesma forma que se inventou a curadoria algorítmica e o processamento automatizado de dados, que modulam comportamentos e escolhas políticas, é preciso desenvolver sistemas de autocontrole dessa máquinas, para que elas funcionem como instrumento de defesa da espécie humana, e não ferramenta de ataque (SAMPAIO, 2020, p. 66).

Seguindo esta perspectiva, o Programa de Desenvolvimento das Nações Unidas (PNUD) vem desenvolvendo, em colaboração com o Instituto Alan Turing no Reino Unido, um modelo computacional que auxilia formuladores de políticas públicas na solução de problemas relacionados à fome, à desigualdade de gênero, à gestão orçamentária, além da busca de caminhos possíveis e exequíveis para a concretização dos Objetivos de Desenvolvimento Sustentável da ONU.

A ferramenta de inteligência artificial, denominada Policy Priority Inference (PPI) (THE 10 A respeito, o termo stakeholder pode ser designado para qualquer pessoa, parceiro, entidade, organização que seja parte interessada direta ou indiretamente na atuação da empresa.

11 De acordo com a pesquisa elaborada em 2018 pelo Akatu, $38 \%$ dos consumidores adotaram hábitos de consumo mais sustentáveis, ao passo que $59 \%$ dos entrevistados creem que as empresas devem agir além do que está prescrito em leis para o benefício da coletividade, demonstrando como o mercado de consumo valoriza o compromisso com a responsabilidade social corporativa. (INSTITUTO AKATU, 2018). 
ALAN TURING INSITUTE, 2021) 12 é operada por algoritmos que simulam um "governo virtual", possibilita o apoio a países, especialmente aqueles menos desenvolvidos ${ }^{13}$, a definir as prioridades de governo, elevar a eficácia dos gastos públicos e acelerar o cumprimento das metas definidas na Agenda 2030, através da combinação de teoria econômica, ciências de redes, economia comportamental e modelagem baseada em agentes, demonstrando, assim, como a tecnologia de IA pode ajudar organizações, governos e comunidades no processo de tomada de decisões e os impactos na distribuição de recursos nas áreas de saúde, educação e infraestrutura.

Isto posto, ante os novos desafios da tecnologia de algoritmos e do atual cenário de responsabilidades compartilhadas, é necessária a atuação conjunta e transparente das instituições políticas estatais e atores privados da sociedade, principalmente do setor empresarial, para enfrentar a realidade virtual vigente e a estabilidade das relações por ela eregidas, de modo a assegurar os valores democráticos e a proteção de direitos e garantias fundamentais no ciberespaço.

\section{CONCLUSÃO}

Com os avanços tecnológicos, o fenômeno da intensa globalização, o rompimento de fronteiras comerciais e inovações no mercado de consumo, o setor empresarial demonstrou, mais uma vez, o comando desproporcional que exerce no sistema político. Ao longo do trabalho, restou evidenciado o papel de influência das corporações na esfera econômica e política, que por diversas vezes, preconizam interesses próprios em detrimento aos interesses do Estado ou da coletividade.

Além da Corporocracia, uma nova ordem de governança se instaurou com a expansão dos sistemas algorítmicos, a denominada Algocracia, transferindo uma parcela de poder das mãos do povo para as mãos dos gigantes da tecnologia operados por algoritmos. Esse sistema de codificação de dados tem a habilidade de traças perfis, discursos e mensagens personalizados, ameaçando e enfraquecendo a democracia na era digital.

Dentre algumas estratégias formuladas para conter a ameaça algorítmica nas sociedades democráticas destacam-se a criação de mecanismo de cooperação e mediação entre atores públicos e privados, através de modelos de parceria para investigação e regulação do modus operandi dos algoritmos e seus efeitos na comunidade, bem como fluxo transparente e acessível de informações e dados veiculados.

O déficit de transparência digital apenas reforça o risco dos algoritmos nos ambientes democráticos, ainda que estejam se desenvolvendo, posto que a coleta e o uso indiscriminado de

12 Instituto nacional de dados e inteligência artificial do Reino Unido, o Alan Turing Institute desenvolveu o método computacional PPI com o propósito de fornecer aconselhamento governamental às estruturas públicas sobre as prioridades e necessidades políticas de determinada comunidade, para alcance dos Objetivos de Desenvolvimento Sustentável da ONU. In: ALAN TURING INSITUTE. Disponível em: https://www.turing.ac.uk/research/researchprojects/policy-priority-inference. Acesso em: 31 jan. 2021.

13 A abordagem em PPI foi utilizada em estudos de caso na América Latina (Uruguai, Colômbia e México), no intuito de garantir a eficácia do desenvolvimento sustentável, sobretudo no atual período pandêmico, no qual recursos foram redistribuídos e os sistemas sobrecarregados. Inserido nesse contexto, o PPI pode ser aplicado para melhor direcionamento de políticas públicas. In: UNITED NATIONS DEVELOPMENT PROGRAMME. Disponível em:

https://www.latinamerica.undp.org/content/rblac/en/home/presscenter/pressreleases/2020/supercharging-sustainabledevelopment-with-a-new-policy-priority.html. Acesso em: 31 jan. 2021. 
dados pessoais combinados com a vigilância pervasiva e seletiva daquilo que o usuário deseja ler, ouvir ou assistir concorrem para a polarização da opinião pública e para distorção da realidade.

Por conseguinte, o reconhecimento da responsabilidade social corporativa e da necessidade da inclusão de diversidade digital, da governança democrática e da participação civil da Internet contribuem para construção da cidadania empresarial e humana, online e off-line, cada vez mais fragmentadas e plurais.

\section{REFERÊNCIAS}

69 of the richest 100 entities on the planet are corporations, not governments. In: GLOBAL JUSTICE NOW. United Kingdom, 17 out. 2018. Disponível em: https://www.globaljustice.org. uk/news/2018/oct/17/69-richest-100-entities-planet-are-corporations-not-governments-figuresshow. Acesso em: 13 abr. 2020.

BARROSO, Luís Roberto. Neoconstitucionalismo e constitucionalização do direito (o triunfo tardio do direito constitucional no Brasil). Revista de Direito Administrativo, Rio de Janeiro, v. 240, p. 1-42, abr./jun. 2005. Disponível em: http://bibliotecadigital.fgv.br/ojs/index.php/rda/ article/view/43618. Acesso em: 05 abr. 2020.

BRASIL. [Constituição (1988)]. Constituição da República Federativa do Brasil (1988). Brasília: Presidência da República, 1988. Disponível em: http://www.planalto.gov.br/ccivil_03/ constituicao/constituicaocompilado.htm. Acesso em: 05 abr. 2020.

DANAHER, John. A threat of algocracy: reality, resistance and accommodation. Philosophy \& Technology, Switzerland, v. 29, n. 3, p. 245-268, jan. 2016. Disponível em: https://philpapers. org/archive/DANTTO-13.pdf. Acesso em: 28 out. 2020.

DOWBOR, Ladislau. Corporações e poder político: notas do front. In: BERRÓN, Gonzalo; GONZÁLES, Luz (org.). A privatização da democracia: um catálogo da captura corporativa no Brasil. São Paulo: IIEP; Vigência, 2016. Disponível em: http://www.vigencia.org/wp-content/ uploads/2016/08/Vige\%CC\%82ncia_Cata\%CC\%81logo_FINAL-1.pdf. Acesso em: 15 jan. 2021.

GALINDO, Cristina. Quando as empresas são mais poderosas que os países. EI País, Economia, 07 nov. 2017. Disponível em: https://brasil.elpais.com/brasil/2017/11/03/ economia/1509714366_037336.html. Acesso em: 15 jan. 2021.

INSTITUTO AKATU. Panorama do consumo consciente no Brasil: desafios, barreiras e motivações. In: BERRÓN, Gonzalo; GONZÁLES, Luz (org.). São Paulo: IIEP; Vigência, 2018. Disponível em: https://www.akatu.org.br/arquivos/Pesquisa_akatu_apresentacao.pdf. Acesso em: 10 maio 2020.

MELO NETO, Francisco; FRÓES, César. Responsabilidade social e cidadania empresarial. 
São Paulo: Qualitymark, 1999.

MÜLLER, Friedrich. Quem é o povo? a questão fundamental da democracia. 3 ed. São Paulo: MaxLiminad, 2003.

SAMPAIO, José Adércio Leite. A declaração universal dos direitos humanos nos espaços digitais: uma necessidade em tempos cibernéticos. Revista Jurídica Unicuritiba, Curitiba, v. 4, n. 61, p. 30-39, 2020. Disponível em: http://revista.unicuritiba.edu.br/index.php/RevJur/article/ view/4451.Acesso em: 28 out. 2020.

SARLET, Ingo Wolfgang. Liberdade de expressão, regulação e discurso de ódio - O caso GNEA. Revista Consultor Jurídico, São Paulo, 23 nov. 2018. Disponível em: https:/www.conjur. com.br/2018-nov-23/direitos-fundamentais-liberdade-expressao-regulacao-discurso-odio-gnea. Acesso em: 26 out. 2020.

SEN, Amartya. Desenvolvimento como liberdade. São Paulo: Companhia das Letras, 2000.

SILVEIRA, Sérgio Amadeu da. Democracia e os códigos invisíveis: como os algoritmos estão modulando comportamentos e escolhas políticas. São Paulo: SESC, 2019.

SILVEIRA, Sérgio Amadeu da. Empresas de tecnologia têm o direito de excluir usuários de suas redes sociais? NÃO. Folha de São Paulo, Opinião, 23 jan. 2021. Disponível em: https://www1. folha.uol.com.br/opiniao/2021/01/empresas-de-tecnologia-tem-o-direito-de-excluir-usuarios-desuas-redes-sociais-nao.shtml. Acesso em: 24 jan. 2021.

SOARES, Mário Lúcio Quintão. Teoria do estado: o substrato clássico e os novos paradigmas como pré-compreensão para o direito constitucional. Belo Horizonte: Del Rey, 2001.

STARK, Birgit et al. Are algorithms a threat to democracy? the rise of intemediares: A challenge for a public discourse. Berlim: AlgorithmWatch, 2020. Disponível em: https:// algorithmwatch.org/wp-content/uploads/2020/05/Governing-Platforms-communications-studyStark-May-2020-AlgorithmWatch.pdf. Acesso em: 20 out. 2020.

THE ALAN TURING INSTITUTE. Polyce priorite inference. London, 2021. Disponível em: https://www.turing.ac.uk/research/research-projects/policy-priority-inference. Acesso em: 31 jan. 2021.

UNITED NATIONS DEVELOPMENT PROGRAM. Supercharging sustainable development with a new policy Priority tool from the Turing backed by UNPD. Disponível em: https://www.latinamerica.undp.org/content/rblac/en/home/presscenter/pressreleases/2020/ supercharging-sustainable-development-with-a-new-policy-priority.html. Acesso em: 31 jan. 2021.

VELOSO, Adriana Meireles. Algoritmos, privacidade e democracia ou como o privado nunca foi tão político como no século XXI. Tese (Doutorado em Ciência Política) Universidade de Brasília (UNB), Brasília, 2020. 181 f. Disponível em: https://repositorio.unb.br/ bitstream/10482/39182/1/2020_AdrianaVelosoMeireles.pdf. Acesso em: 22 out. 2020. 
ZUBOFF, Shoshana. The age of surveillance capitalism: the fight for a human future at the new frontier of power. Londres: Profile Books, 2019.

Como citar: DURÃO, Pedro; PINTO, Juliana Araujo. Algocracia S/A: O Poder Das Corporações E Seus Algoritmos Nas Sociedades Democráticas. Revista do Direito Público, Londrina, v. 16, n. 3, p. 192-206, dez. 2021. DOI: 10.5433/24157-108104-1.2021v16n3p.192. ISSN: 1980-511X

Recebido em: 21/03/2021

Aprovado em: 11/10/2021 